\title{
1 A BIOECONOMIC APPROACH TO OPTIMIZE MUSSEL CULTURE \\ 2 PRODUCTION
}

3 Runnig head: Bioeconomic approach for mussel culture

4 Isabel Fuentes-Santos, Alhambra M. Cubillo ${ }^{1}$ and Uxío Labarta*

5 CSIC. Instituto de Investigaciones Marinas, Eduardo Cabello, 6, 36208 Vigo, Spain.

$6 \quad *$ corresponding author: e-mail: labarta@,iim.csic.es. Tel.: +34 986231930 - Ext. 214;

$7 \quad$ Fax: +34986292762

8 isafusa@iim.csic.es, alhambrag@iim.csic.es

9

101 Actual address: IMAR - Institute of Marine Research, Centre for Ecological Modelling, IMAR-

11 DCEA, Faculty of Science and Technology, Qta Torre, 2829-516 Monte de Caparica, Portugal 


\section{Abstract}

\section{Keywords}

The fast rise of aquaculture practices during the last decades has increased the need of adopting culture strategies to optimize production and guarantee the sustainability of the sector. This study aims to provide a management tool to help mussel farmers identify optimal culture strategies and use production inputs efficiently. For this purpose, we evaluated the productivity and efficiency of different stocking densities and culture lengths by the joint application of parametric and non-parametric frontier analysis at the farm-scale. The translog production function outperformed the Cobb-Douglas model currently applied in most farm-scale frontier analyses. This model estimates that the optimal culture density is ca. $700 \mathrm{ind} / \mathrm{m}$, given that at lower densities efficiency decreases (under-usage of available space) and mussel quality did not improve, and at higher densities mortality and dislodgements from the ropes led to economic losses. This work also showed that marginal analysis does not provide an accurate estimation of the economic efficiency when unitary costs and prizes are not constant. According to the Malmquist indices mussel farmers should shorten the culture period in order to improve their productivity. All these results support the joint use of parametric and non-parametric frontier analysis as management tool for optimizing input use and scheduling aquaculture production.

Aquaculture management, culture strategies, Malmquist index, marginal analysis, stochastic frontier function. 


\section{Introduction}

Aquaculture is the fastest growing food sector in the world, with production increasing at an annual rate of $7.8 \%$ between 1990 and 2010, and an expected annual growth up to $4.14 \%$ from 2014 to 2022 (FAO 2014). Nowadays aquaculture provides $50 \%$ of the fishery output for human consumption, of which $23.6 \%$ is shellfish culture (14.2 million tons; FAO 2014). With $80 \%$ of the total consumed shellfish being cultured, this is an important activity in many coastal zones worldwide. The fast rise of aquaculture practices points out the need of adopting culture strategies in order to optimize production and guarantee the sustainability of the sector. Industry-scale frontier analysis has been widely used to assist producers and decision-makers in identifying optimal production system designs, operation management strategies, and alternative development and policy approaches, although its use in aquaculture is limited when compared with agriculture or other manufacturing industries (Iliyasu et al., 2014). Farm-scale analysis of productivity and environmental impact of shellfish aquaculture has been addressed by Ferreira et al., (2007) and Hawkins et al., (2013), which developed simulation procedures based on the interaction between suspensionfeeding bivalves and the environment.

The productivity and efficiency measures introduced by Farrell, (1957) motivated the development of several parametric and nonparametric techniques for frontier analysis. The stochastic frontier production function (SFPF) approach involving econometric estimation of parametric functions (Aigner et al., 1977; Meeusen and Broeck, 1977), and data envelopment analysis (DEA) involving linear programming (Charnes et al., 1978) are the most popular techniques used in frontier analysis. The main advantage of the SFPF is that it can decompose the deviation from the frontier in stochastic noise and technical inefficiency components. The main drawback of this 
61 approach is the need of a functional form for the technology and the inefficiency error

62 term, as the misspecification of the model can lead to biased estimations and wrong 63 conclusions. DEA eliminates the need of a parametric assumption, but due its 64 deterministic nature, this approach attributes all deviations from the frontier to 65 inefficiency effects overlooking the stochastic noise. This drawback was partially 66 overcame by the bootstrap procedure introduced by Simar and Wilson, $(2000,1998)$ to 67 create confidence intervals for DEA scores. As neither approach is strictly preferable, 68 Murillo-Zamorano and Vega-Cervera, (2001) suggested that the joint use of both 69 techniques can improve the accuracy of frontier analysis. Nevertheless, as in other areas of knowledge, economic efficiency of aquaculture production has been analyzed either by stochastic frontier production functions or DEA (see Iliyasu et al., (2014) and references therein) and to our knowledge the joint use of both techniques is still lacking. and ShellSIM (Hawkins et al., 2013) are farm-scale models that simulate the interactions between suspension-feeding bivalves and the environment in order to estimate carrying capacity, shellfish production and quantify the ecological impact of aquaculture on the ecosystem. These models can be a useful management tool for both farmers and regulators, as they allow the development of culture strategies in order to optimize economic profits and minimize the environmental impact. Both procedures use marginal analysis based on a Cobb-Douglas SFPF model with stocking biomass as the unique variable input, in order to determine the optimal culture density. The dynamic ecological-economic model proposed by Nobre et al., (2009) also uses a Cobb Douglas model to estimate the marginal productivity of capital and labour. To our knowledge, more general parametric models, such as the translogarithmic SFPF, and nonparametric frontier analysis have not been used at farm-scale level. 
The extensive culture of the blue mussel (Mytilus galloprovincialis), with a production volume that ranged between $200,000-300,000$ tonnes and a production value that exceeded 100 million Euros in 2012 (www.pescadegalicia.com), is the main aquaculture industry in Galicia. Mussels are cultured in floating systems (rafts) consisting of a $500 \mathrm{~m}^{2}$ wood structure anchored to the seafloor, from which culture ropes and/or seed collectors are suspended. Nowadays, the number of ropes per raft is limited to 500. Besides, the maximum number of rafts allowed in the Galician Rias (ca. 3300) has been reached. Mussel culture is scheduled according to the availability of natural resources for feeding and seed recruitment, the biological cycle of mussels and the fluctuations of market demand (Labarta et al., 2004). Subjected to all these constraints, mussel farmers have focused on optimizing the use of available space in the raft to maximize profits, following two strategies: increasing culture densities and/or decreasing the length of the culture cycle.

This study aims to develop a management tool that allows mussel farmers to identify optimal farm-based culture strategies and use production inputs efficiently. To this purpose, we conducted an experiment to evaluate the performance of different culture strategies (testing different cycle lengths and mussel stocking densities) by the joint application of parametric and non-parametric frontier analysis at the farm-scale. We applied parametric frontier analysis to determine the optimal culture density and evaluated whether marginal analysis can be applied to estimate the economic efficiency of suspended mussel culture. We estimated the nonparametric Malmquist indices to analyze the productivity change along the culture period in order to determine the optimal cycle length. 
110

111

112

113

114

115

116

117

118

119

120

121

122

123

124

125

126

127

128

129

130

131

132

133

\section{Material and Methods}

\subsection{Experimental design}

The study area was located in the raft polygon of Lorbé in Ría de Ares-Betanzos, on the NW coast of Spain $\left(43^{\circ} 22^{\prime} 39.20^{\prime}{ }^{\prime} \mathrm{N}, 8^{\circ} 12^{\prime} 39.77^{\prime \prime} \mathrm{W}\right)$. This Ría has great bioeconomical importance due to extensive mussel culture (Mytilus galloprovincialis).

Data were collected during the traditional thinning-out to harvest period, employing the culture and handling techniques used by the local industry (Labarta et al., 2004). In late April 2008, mussels from collector ropes deployed 8 months before (September 2007) were thinned out at seven densities (treatments), encompassing the current commercial densities in Galicia $(600-800 \mathrm{ind} / \mathrm{m})$. The mean shell length of these mussels was $48.78 \mathrm{~mm}$ ( $\mathrm{sd}=1.27)$, which is close to the minimum commercial size $(50 \mathrm{~mm})$. Stocking biomass $(\mathrm{Kg} /$ rope $)$ was measured as rope weight at the beginning of the culture (in this case at thinning-out). Production costs $(€ /$ rope $)$ were obtained from a survey of several mussel aquaculture farms, and included labour, estimated as time spent per rope for thinning-out and harvesting, boat fuel consumption for deploying and harvesting the ropes, and raft occupation costs (Table 1, Appendix I). As mussels were obtained from collector ropes, their cost $(€ / \mathrm{Kg})$ was estimated as the occupation cost of these collector ropes in the raft.

Production data were collected monthly from late May to late November (see details in (Cubillo et al., 2012c) so that the length of growing season or cycle length (days) can be considered as an input. Density was calculated as the number of mussels per linear meter of rope (ind $/ \mathrm{m})$. Total production $(\mathrm{Kg} / \mathrm{rope})$ was estimated as the weight of commercial ( $>50 \mathrm{~mm}$ shell length) mussels. Production prices $(€ / \mathrm{Kg})$ and revenues $(€ /$ rope) were estimated taking into account the two markets: fresh sale 
134 (mussels sold as fresh product) and industry sale (frozen, canned and processed 135 mussels). Fresh sale prices are based on mussel size, measured as number of mussels 136 per $\mathrm{Kg}$ (ind/Kg), according to the average classification used by several distribution 137 companies (Pérez-Camacho et al., 2013): Extra1 ( $<21 \mathrm{ind} / \mathrm{Kg}, 1 € / \mathrm{Kg})$, Extra2 (21-27 $138 \mathrm{ind} / \mathrm{Kg}, 0.9 € / \mathrm{Kg})$, Large $(28-35 \mathrm{ind} / \mathrm{Kg}, 0.75 € / \mathrm{Kg})$, Normal $(36-45 \mathrm{ind} / \mathrm{Kg}, 0.6 € / \mathrm{Kg})$ and Small (46-70 ind $/ \mathrm{Kg}, 0.5 € / \mathrm{Kg}$ ). Industry sale prices build on mussel quality in terms of mussel size (ten categories ranging from $>276$ to $<98 \mathrm{ind} / \mathrm{Kg}$ tissue), and Condition Index measured as the meat to total weight ratio of mussels (from $12 \%$ to $27 \%$ ), according to a pool of processing industries, so that small mussel ( $>276 \mathrm{ind} / \mathrm{Kg}$ tissue) prices ranged between 0.22 and $0.50 € / \mathrm{Kg}$ and large mussel $(<98 \mathrm{ind} / \mathrm{Kg}$ tissue) prices between 0.35 and $0.78 € / \mathrm{Kg}$.

\subsection{Data analysis.}

We first conducted an exploratory analysis of the variables involved in the mussel culture process. We applied two-way repeated measures ANOVA to test the effects of density treatment and cycle length on production and product quality. In addition, we applied generalized additive models (GAM) to estimate the effect of stocking biomass and cycle length on the profits obtained by fresh and industry sale, and to analyze the differences between both. Section 2.2.1 provides detailed information about the GAM model. Model fitting was conducted with the mgev package of $\mathrm{R}(\mathrm{R}$ Core Team, 2013; Wood, 2006a)

The analysis of productivity and efficiency was conducted by the joint use of parametric (SFF) and non-parametric techniques (DEA). We applied Stochastic frontier analysis, considering stocking biomass (Kg/rope) and cycle length (days) as inputs, and 
158 production carrying capacity of the system without exceeding it, i.e. the optimal density 159 treatment. In addition, we estimated the non-parametric Malmquist indices for 160 productivity, efficiency and technology change, considering stocking biomass (Kg/rope) 161 and culture costs (€/rope) as inputs and total production $(\mathrm{Kg} /$ rope $)$ or profits (€/rope), as 162 outputs. This analysis allows us to determine the optimal cycle length for each market 163 and the most profitable market for each cycle length. The parametric and non164 parametric frontier analysis were conducted with the frontier (Coelli and Henningsen, 165 2011) and FEAR (Wilson, 2008) packages of R. Sections 2.2.2 and 2.2.3 provide 166 information about these procedures.

\subsubsection{Generalized additive models (GAM)}

168
For both fresh and industry sale, we fitted the profits $(\mathrm{P}, € /$ rope $)$ obtained as the difference between costs and revenues, according to cycle length ( $T$, days) and stocking biomass ( $\mathrm{S}, \mathrm{Kg} /$ rope) by generalized additive models (GAM) with second order interaction (Hastie and Tibshirani, 1990; Wood, 2006b). As the response variables are normal, we assumed a Gaussian family with identity link function (Hastie and Tibshirani, 1990; Wood, 2006a). Our model can be expressed as follows:

$$
E(P)=\alpha+f_{1}(S)+f_{2}(T)+f_{12}(S, T)
$$

where, for each transaction, $E(P)$ are the estimated profits, $\alpha$ is the intercept, $f_{j}, \mathrm{j}=1,2$ the smooth terms for each covariate, which were represented by penalized regression splines, and $f_{12}$ the smooth term for the interaction between stocking biomass and cycle length, estimated using a scale-invariant tensor product of penalized regression splines (Wood, 2006b). Finally, we obtained 95\% confidence intervals for the predicted values in order to compare profits between fresh and industry sale. 
181

182

2.2.2. Stochastic frontier production function (SFPF) with a model for technical inefficiency effects and marginal analysis

We applied one-step stochastic frontier analysis (see details in Appendix II) to estimate the potential production and efficiency levels of the different density treatments. Model selection was conducted by several likelihood ratio tests (Table 2). Our data rejected the Cobb-Douglas model for the stochastic frontier function (Appendix II). Total efficiency, deterministic efficiency and independence between inefficiency and density treatment were also rejected. Thus, we fitted the SFPF for total production ( $\mathrm{B}, \mathrm{Kg} / \mathrm{rope}$ ) by a translogarithmic model with stocking biomass ( $\mathrm{S}$, $\mathrm{Kg} /$ rope) and cycle length ( $\mathrm{T}$, days) as inputs and density treatment as inefficiency factor (Z) (Battese and Broca, 1997; Battese and Coelli, 1995). This model can be expressed as follows:

$$
\begin{aligned}
\ln B_{i t} & =\beta_{0}+\beta_{1} \ln S_{i t}+\beta_{2} \ln T_{i t} \\
& +\frac{1}{2}\left(\beta_{11}\left(\ln S_{i t}\right)^{2}+2 \beta_{12} \ln S_{i t} \ln T_{i t}+\beta_{22}\left(\ln T_{i t}\right)^{2}\right)+V_{i t}-U_{i t}
\end{aligned}
$$

where $U_{i t}$ is the estimator of the technical inefficiency, $T E_{i t}=\exp \left(-U_{i t}\right)$, and can be expressed as $\quad U_{i t}=z_{i t} \delta+W_{i t}$, where, $\mathrm{z}_{\mathrm{it}}$ is the vector of dummy variables associated to each density treatment, $\delta$ is the associated vector of parameters and $W_{i t}$ are random error terms $\left(N\left(0, \sigma_{w}{ }^{2}\right)\right)$. Positive coefficients $(\delta>0)$ indicate relative technical inefficiency while negative coefficients $(\delta<0)$ point out relative technical efficiency. The more the estimated value differs from zero, the stronger the efficiency/inefficiency.

In order to measure the effect of any input change on total production we estimated the output elasticity for each input (Appendix II). The sum of these parameters yields the return to scale (RTS), which measures the percentage change in 
203 output from a $1 \%$ change in all inputs. When RTS $>1($ RTS $<1)$ the production

204 function exhibits increasing (decreasing) returns to scale, i.e. a simultaneous increase in

205 all inputs by a certain percentage results in greater (lower) percentage increase in 206 output. If $\mathrm{RTS}=1$, the farm has constant returns to scale, implying that a proportionate

207 increase in inputs will lead to the same increase in output. The cross-elasticity of 208 substitution $\mathrm{H}_{\mathrm{jk}}$, (Chiang et al., 2004) was estimated to measure the relationship between 209 inputs (Appendix II). $H_{12}>0$ indicates that the inputs are jointly complementary, i.e. we 210 need to increase stocking biomass and cycle length together to raise total production. $211 H_{12}<0$ indicates a competitive relationship between inputs, i.e. a decrease in stocking 212 biomass could be compensated elongating the culture period, and viceversa.

213 Finally, we analyzed the economic efficiency of the stocking biomass (S) by comparison between the incremental benefit of an additional unit (VMP) and its incremental cost $\left(\mathrm{P}_{\mathrm{x}}\right)$. If the value of the marginal product (VMP) of an input is greater than its cost $\left(\mathrm{P}_{\mathrm{x}}\right)$, profit could be raised increasing the use of that input, and conversely.

217 The efficient use of an input is achieved when the value of its marginal product equals 218 its price. Marginal analysis is usually built under some regularity conditions: (i) inputs are unlimited, (ii) inputs purchase and output sales are made in a perfect competitive market situation, (iii) the farm is a small production system that sells only this product and (iv) mussel seed is the unique variable input, as other cost (such that lease or labour) are fixed (Ferreira et al., 2007). These conditions are not necessarily true in mussel suspended culture. On one hand, on contrast with assumption (iv) the relative raft occupation, labour and transport costs decrease as the stocking biomass increases (see Fig. A1 in Appendix I). On the other hand, as explained in Section 2.1 mussel prices depend on mussel size and quality. In this work, we conduct the marginal analysis for each cycle length taking into account the variability of costs and prices 
228 along the density gradient. Thus, for each density treatment and cycle length, we

229 estimate the ratio VMP/Px and check whether these values equal 1 to indentify optimal 230 input use.

231

232

\subsubsection{Malmquist productivity indices}

233

Productivity change between sequential months for each density treatment was analyzed through the input-based Malmquist productivity, efficiency and technology indices. We obtained these indices following the estimation and bootstrap methods proposed by Simar and Wilson (1999) under the assumption of constant returns to scale. Productivity was measured in terms of total production (Kg/rope) and revenue (€/rope) for both fresh and industry sale. As we are interested in productivity change over time, we cannot consider cycle length as input, as we did above. Thus, our inputs are stocking biomass ( $\mathrm{Kg} / \mathrm{rope})$, which depend on the density treatment but remains constant over time, and culture costs (defined as the sum of labour, transport and occupation, Appendix I), which depend on both density treatment and cycle length. is defined as:

$$
M_{i}\left(t_{1}, t_{2}\right)=\frac{D_{i}^{t_{2} / t_{2}}}{D_{i}^{t_{1} / t_{1}}}\left(\frac{D_{i}^{t_{2} / t_{1}}}{D_{i}^{t_{2} / t_{2}}} \frac{D_{i}^{t_{1} / t_{1}}}{D_{i}^{t_{1} / t_{2}}}\right)^{1 / 2}=\varepsilon_{i}\left(t_{1}, t_{2}\right) F_{i}\left(t_{1}, t_{2}\right),
$$

247 where $D_{i}^{t_{j} / t_{k}}$ is the Shephard input distance function for treatment $i$ at time $t_{j}$ relative to 248 the technology at time $t_{k}$ (Shephard, 1970). Values of $M_{i}\left(t_{1}, t_{2}\right)<1$ indicate 
249

250

251

252

253

254

255

256

257

258

259

260

261

262

263

264

265

improvements in productivity, while values $M_{i}\left(t_{1}, t_{2}\right)>1$ indicate productivity regress from $t_{1}$ to $t_{2}$. When the estimated Malmquist index is 1 , there is no productivity change.

The Malmquist productivity index can be decomposed into an index of inputbased efficiency, the ratio outside the bracket in (3), and an index of input-based technology change, the geometric mean of the two ratios inside the bracket in (3), which measure the shift in the production frontier. As with $M_{i}\left(t_{1}, t_{2}\right)$, values of $\varepsilon_{i}\left(t_{1}, t_{2}\right)$ and $T_{i}\left(t_{1}, t_{2}\right)$ lower (greater) than unity reflect efficiency/technology progress (regress) between times $t_{1}$ and $t_{2}$.

\section{Results}

\subsection{Exploratory analysis}

Fig. 1a-1d shows an exploratory analysis of the population dynamics along the experiment. We observe a significant effect of cycle length, density treatment and their interaction (2-way repeated measures ANOVA, $\mathrm{p}<0.001$ ) on density (ind $/ \mathrm{m}$ ), total production $(\mathrm{Kg} / \mathrm{rope})$ and mussel size (ind $/ \mathrm{Kg}$ ), while meat yield (Condition index), which is mainly determined by the reproductive cycle of mussels, depended only on cycle length, reaching its maximum values from June to September.

Total production (Fig 1b, Kg/rope) increased up to August for the higher density treatments $(570-1150 \mathrm{ind} / \mathrm{m})$ and up to September for the lower $(220-500 \mathrm{ind} / \mathrm{m})$. Despite the negative effects of overcrowding on mussel survivorship (Fig. 1a) and growth (Fig. 1c) total production increased along the density gradient. In June, commercial mussels ( $\mathrm{L}>50 \mathrm{~mm}$ ) accounted for $90 \%$ total rope weight, and from August onwards the percentage was over the $99 \%$. For all density treatments, mussels reached the Medium commercial category $(66 \mathrm{~mm}$ and $37 \mathrm{ind} / \mathrm{Kg}$ ) in August and the Large 
273 category $(70 \mathrm{~mm}$ and $33 \mathrm{ind} / \mathrm{Kg})$ in September. Only two density treatments, $220 \mathrm{ind} / \mathrm{m}$

274 and $700 \mathrm{ind} / \mathrm{m}$ reached the Extra2 category $(73 \mathrm{~mm}$ and $29 \mathrm{ind} / \mathrm{Kg}$ ) in November.

275 Therefore, fresh sale prices $(€ / \mathrm{Kg})$ increased up to September (Fig 1e) and remained

276 constant thereafter (Fig 1e). Industry-sale prices $(€ / \mathrm{Kg})$, as expected given their

277 dependence on the condition index, were only affected by cycle length and reached

278 maximum values between June and September (Fig 1f). Due to the small differences

279 found in the size and quality of mussels among density treatments, the revenues per $\mathrm{Kg}$

280 were similar (Fig. 1e and 1f), while the revenues per rope increased along the density

281 gradient for both fresh and industry sale (Fig. 2).

Figs. 2 and 3 show the estimated profits for fresh (Adjusted R2 $=0.801$ ) and industry sale (Adjusted R2 $=0.77$ ). For all density treatments, fresh sale profits 284 increased over time, although this increase ameliorated from September onwards. Industry sale profits increased up to August and decreased thereafter. The higher densities $(>500 \mathrm{ind} / \mathrm{m})$ amortized culture costs in June $(\mathrm{L} \approx 57 \mathrm{~mm})$ by industry sale and in July $(\mathrm{L} \approx 61 \mathrm{~mm}$ ) by fresh sale, while the lower densities needed an extra month to be profitable. Smaller mussels (up to August) provided higher profits through industry sale due to the increase in meat yield during summer, while larger mussels $(>70 \mathrm{~mm})$ are more suitable for fresh sale. In August, industry sale overcame at least a 15\% fresh sale profits, whereas in September fresh sale overcame at least a $26 \%$ industry sale profits. production introduced in section 2.2.2. Both output elasticities are positive and close to 0.5 , implying that a $1 \%$ increase in any input would increase production by $\approx 0.5 \%$, though the elasticity for cycle length $(0.50)$ is significantly higher than the elasticity for 
297 stocking biomass $(0.47)(\mathrm{t}$-test, $\mathrm{p}=0.042)$. We obtained constant returns to scale $(\mathrm{RTS}=$

$2980.973=1$; $\mathrm{t}$-test, $\mathrm{p}$-value $>0.05)$, so that a given simultaneous increase in culture days 299 and stocking biomass will give the same percentage increase in production. The Hicks 300 substitution elasticity for stocking biomass and cycle length $\left(\mathrm{H}_{12}=0.905>0\right)$ indicates 301 a complementary relationship between inputs, i.e. they need to be increased together to 302 raise total production. Finally, our results show that only $1.14 \%$ of the deviation from 303 the stochastic frontier can be attributed to technical inefficiency.

The lower half of Table 3 shows the estimated inefficiency effects of each culture density and the respective technical efficiencies (TE). Relative inefficiency $(\delta>$ 0) was statistically significant for mussels cultured at 220-570 and $800 \mathrm{ind} / \mathrm{m}$, while relative efficiency $(\delta<0)$ was found for $1150 \mathrm{ind} / \mathrm{m}$. Despite density-dependent mussel losses, technical efficiency increased with stocking biomass, being $700 \mathrm{ind} / \mathrm{m}$ and 1150 ind $/ \mathrm{m}$ (which achieved total efficiency) the most efficient densities, whereas the lowest density operated $51.6 \%$ below the production frontier.

The results of the economic efficiency analysis for stocking biomass are shown in Fig. 4. Marginal costs (Px) increased linearly along the culture period and decreased along the density gradient. For fresh sale, marginal benefits (VMP) increased over time (Tukey HSD, p-value < 0.001) and decreased over the density gradient, 1150 reported the lower economic efficiency and $700-800 \mathrm{ind} / \mathrm{m}$ were less efficient than $220-500 \mathrm{ind} / \mathrm{m}$ 316 (Tukey HSD, p-values < 0.001). For industry sale, the VMP stabilized in August 317 (Tukey HSD, p-value $>0.1$ ) and the densities of 700, and $1150 \mathrm{ind} / \mathrm{m}$ reported lower economic efficiency than 220-570 ind/m (Tukey HSD, p-value $<0.01$ ). For both fresh an industry sale, the ratio between VMP and the marginal costs (Fig 4, bottom) shows the same temporal pattern as the VMP and remained constant along the density gradient

321 (Tukey HSD, p-value > 0.05). As all ratios are below 1, optimal input use was not 
322 reached for any market. Comparison between markets reported higher relative

323 efficiency for fresh sale than for industry sale from September onwards for all density 324 treatments.

325

326

327

\subsection{Malmquist productivity indices}

Consistent with Färe et al. (1992) we report the reciprocals of the original nonparametric indices (Tables 4-6 and Fig. 5), so that numbers greater than unity denote progress while numbers lower than unity denote regress. As expected given the low proportion of deviation from the production frontier attributed to technical inefficiency $(1.14 \%)$, its effect on Malmquist productivity indices was very low, and changes in productivity over time were mainly explained by shifts in the production frontier.

The estimated indices for efficiency change (Table 4-6, Fig 5 centre) did not show a clear pattern along culture, except for the highest density $(1150 \mathrm{ind} / \mathrm{m})$ that reported constant efficiency over time.

Total production and fresh sale revenues reported technology progress up to September. The production frontier stagnated thereafter for the two lower densities, while the higher densities suffered a regress during October followed by a new increase during the last month. For industry sale prices technology progress ceased in August (Table 4-6, Fig 5 right).

Finally, the Malmquist indices reported productivity improvements up to September in all density treatments for total production and fresh sale revenues, while for industry sale some density treatments suffered productivity regress in September (Table 4-6, Fig 5 left). The productivity losses observed in October for the higher 
344 densities $(\geq 500 \mathrm{ind} / \mathrm{m})$ and November for the lower $(\leq 570)$ were caused by reductions

345 in potential production and efficiency, respectively.

347 4. Discussion and conclusions

This work provides a productivity analysis for suspended mussel aquaculture at the farm-scale, based on monitoring of mussel growth and survivorship. Prior studies have focused on industry-scale analysis (see Iliyasu et al., (2014) and references therein) or have conducted farm-scale productivity analysis based on simulation models for mussel growth (Ferreira et al., 2007; Hawkins et al., 2013). Most research works on the production frontier in aquaculture have focused on efficiency measurement using either Stochastic Production Frontier (SPF) or Data Envelopment Analysis (DEA). This work incorporates empirical data to productivity analysis and evaluates the performance of different culture strategies (defined as mussel density and cycle length) through the joint application of parametric (SFPF) and non-parametric frontier analysis (Malmquist 358 indices).

This study shows that both parametric (SFPF) and non-parametric (Malmquist indices) approaches reflect the effect of mussel population dynamics (intraspecific competition, mussel growth and mortality) on production. Population dynamics were previously described on the same data set by Cubillo et al., (2012b) and Fuentes-Santos et al., (2013). The former found a negative effect of stocking rate on mussel growth rates, and the later found significant mussel losses at higher density ( $>500 \mathrm{ind} / \mathrm{m})$, being $1150 \mathrm{ind} / \mathrm{m}$ the treatment with the highest mortality. Both studies concluded stronger competition effects at higher densities. 
The current farm-scale productivity analyses use the Cobb-Douglas model

368

369

370

371

372

373

374

(Ferreira et al., 2007; Hawkins et al., 2013; Nobre et al., 2009) to estimate the stochastic frontier function. However, when the effects of the inputs on production are not independent, we need more general models. Following the methodology applied at industry-scale level (Battese and Broca, 1997; Chiang et al., 2004; Iliyasu et al., 2014) we fitted a translog stochastic frontier function with density treatment as efficiency factor, which improved the understanding of multiple dependency and interaction between production inputs (stocking biomass and cycle length) and estimates the effect of the density treatment on technical efficiency. The likelihood ratio tests confirmed that the translog model is more accurate than the Cobb Douglas frontier function.

Most of the industry-scale studies in aquaculture have focused on technical efficiency and total production (Iliyasu et al., 2014). However, maximizing biological production does not lead to maximize profits, and management tools should rely on economic instead of technical efficiency. Following Ferreira et al., (2007), which stated that the profit maximization rule is based on marginal principles; we applied marginal analysis to determine the optimal stocking biomass. However, we should note that suspended mussel culture violates the principle of constant production costs (occupation, labour and transport), as these values depend on the density treatment. To estimate the marginal cost of the stocking biomass $(\mathrm{Kg} / \mathrm{m})$ we need to decompose each production cost into a constant part and a part that varies with the density treatment, and sum the latter to the cost of mussels (or mussel seed). However, in practice we cannot determine which proportion of each production cost depends on the density treatment. If we just consider the cost of mussel seed to estimate $\mathrm{P}_{\mathrm{X}}$ we shall underestimate the marginal cost and obtain wrong conclusions in the comparison between density treatments. Estimating $\mathrm{P}_{\mathrm{X}}$ as the sum of mussels, labour and occupation costs provides a 
392 proper comparison between density treatments, but overestimates the marginal cost.

393 Therefore we cannot rely on the comparison between VMP and $\mathrm{P}_{\mathrm{X}}$ to determine the 394 optimal input use in either case. Taking into account these drawbacks and that 395 comparison between markets did not provide further information than that provided by 396 the GAM models, we do not recommend the use of marginal analysis in suspended 397 mussel aquaculture.

The use of the Malmquist productivity indices to measure productive growth at the industry-scale in aquaculture has gained popularity in recent years (Iliyasu et al., 2014). These works focus on optimizing total production, but did not considered economic capacity. Given that culture strategies should focus on maximizing profits instead on maximizing total production, we proposed to estimate the Malmquist productivity indices considering revenues as output. We point out that the variability in output prices regarding the quality of the product and the market (fresh or industry sale) should be taken into account in the economic analysis. These indices measured the change in economic capacity and efficiency along culture and allowed us to determine the optimal cycle length.

The parametric stochastic frontier analysis determined that $700 \mathrm{ind} / \mathrm{m}$ is the optimal culture density. The relative inefficiency observed at lower densities, which did not suffered mortality due to intraspecific competition but did not provide better mussel quality than higher densities, indicates an underuse of the available resources. The relative efficiency of $1150 \mathrm{ind} / \mathrm{m}$, which suffered the strongest competition effects on mussel growth and survivorship (Cubillo et al., 2012a; Fuentes-Santos et al., 2013),

414 indicates that this density exceeded the carrying capacity of the rope. Apart from the 415 economic losses, mussel mortality also implies the increase of biodeposits beneath 416 culture leases that alter the physical and chemical conditions of the bottom sediments, 
417 and thus affect the natural biodiversity. As in (Ferreira et al., 2007; Hawkins et al., 418 2013) models, the environmental effects of mussel culture should be taken into 419 consideration to develop decision making tools that guarantee the sustainability of 420 suspended mussel culture.

The Malmquist productivity, efficiency and technology indices allowed us to determine the optimal cycle length. The risk of productivity regress from October onwards suggests that it is not worth extending the culture beyond September, i.e. when

424 individuals reach lengths of $\approx 70 \mathrm{~mm}$. In addition, the economic analysis points out that 425 farmers would maximize profits in August $(\mathrm{L}=66 \mathrm{~mm})$ by industry sale and September $426(\mathrm{~L}=70 \mathrm{~mm})$ by fresh sale, due to the differences in the type of product that these two 427 markets demand. These results together with the recent shift to smaller sizes $(\mathrm{L} \leq$ $42875 \mathrm{~mm}$ ) in mussel market, highlights the suitability of shortening the current cycle 429 length.

Thus, this work provides a suitable management tool for optimizing input use in aquaculture practices and scheduling production according to market demand. Our

432 results indicate that the current stocking densities in Galician mussel aquaculture (600$433800 \mathrm{ind} / \mathrm{m})$ are close to the optimum culture density $(700 \mathrm{ind} / \mathrm{m})$ and their technical 434 efficiency is above $85 \%$. However, according to the Malmquist indices mussel farmers should shorten the thinning-out to harvest period in order to improve their productivity. 436 In addition to optimizing profits, this reduction of cycle length results in a more 437 efficient use of the available space. 


\section{Acknowledgements}

441 We are grateful to Dolores Fernández Vázquez (PROINSA Mussel Farm Managing 442 Director) and Prof. Enrique Navarro (University of Basque Country) for the critical 443 revision of this work, and M.J. Fernández Reiriz for her valuable comments. We wish to 444 acknowledge PROINSA Mussel Farm and their employees, especially H. Regueiro and 445 M. García for technical assistance. This study was supported by the contract-project 446 PROINSA Mussel Farm, codes CSIC 20061089 and 0704101100001, a CSIC PIE 447 201030E071 project, and Xunta de Galicia PGIDIT09MMA038E. A.M. Cubillo was 448 also funded by a Fundación Juana de Vega postdoctoral fellowship during manuscript 449 preparation.

\section{References}

452

453

454

455

456

457

458

459

460

461

462

463

464

Aigner, D., Lovell, C.A.K., Schmidt, P., 1977. Formulation and estimation of stochastic frontier production function models. J. Econom. 6, 21-37. doi:10.1016/03044076(77)90052-5

Battese, G.E., Broca, S.S., 1997. Functional Forms of Stochastic Frontier Production Functions and Models for Technical Inefficiency Effects: A Comparative Study for Wheat Farmers in Pakistan. J. Product. Anal. 8, 395-414. doi:10.1023/A:1007736025686

Battese, G.E., Coelli, T.J., 1993. A stochastic frontier production function incorporating a model for technical inefficiency effects. Department of Econometrics, University of New England Armidale.

Battese, G.E., Coelli, T.J., 1995. A model for technical inefficiency effects in a stochastic frontier production function for panel data. Empir. Econ. 20, 325-332. doi:10.1007/BF01205442 
465 Charnes, A., Cooper, W.W., Rhodes, E., 1978. Measuring the efficiency of decision

466

467

468

469

470

471

472

473

474

475

476

477

478

479

480

481

482

483

484

485

486

487

488 making units. Eur. J. Oper. Res. 2, 429-444. doi:10.1016/0377-2217(78)901388

Chiang, F.-S., Sun, C.-H., Yu, J.-M., 2004. Technical efficiency analysis of milkfish (Chanos chanos) production in Taiwan — an application of the stochastic frontier production function. Aquaculture 230, 99-116. doi:10.1016/j.aquaculture.2003.09.038

Coelli, T., Henningsen, A., 2011. frontier: Stochastic Frontier Analysis R package version 0.887 .

Cubillo, A.M., Fuentes-Santos, I., Peteiro, L.G., Fernández-Reiriz, M.J., Labarta, U., 2012a. Evaluation of self-thinning models and estimation methods in multilayered sessile animal populations. Ecosphere 3, art71. doi:10.1890/ES1200180.1

Cubillo, A.M., Peteiro, Laura G., Fernández-Reiriz, MJ, Labarta, Uxío, 2012 b. Influence of stocking density on biomass production and survival of mussels ( Mytilus galloprovincialis ) grown in suspended culture., in: Physiomar 12: Proceedings of the 4th Physiomar International Meeting, Santiago de Compostela, Spain, 4th-8th September, 2012. p. 149.

Cubillo, A.M., Peteiro, L.G., Fernández-Reiriz, M.J., Labarta, U., 2012c. Influence of stocking density on growth of mussels (Mytilus galloprovincialis) in suspended culture. Aquaculture 342-343, 103-111. doi:10.1016/j.aquaculture.2012.02.017

Färe, R., Grosskopf, S., Lindgren, B., Roos, P., 1992. Productivity changes in Swedish pharamacies 1980-1989: A non-parametric Malmquist approach. J. Product. Anal. 3, 85-101. doi:10.1007/BF00158770 
Farrell, M.J., 1957. The Measurement of Productive Efficiency. J. R. Stat. Soc. Ser. Gen. 120, 253-290. doi:10.2307/2343100

Ferguson, C.E., 2008. The Neoclassical Theory of Production and Distribution (Cambridge Books). Cambridge University Press.

Ferreira, J.G., Hawkins, A.J.S., Bricker, S.B., 2007. Management of productivity, environmental effects and profitability of shellfish aquaculture — the Farm Aquaculture Resource Management (FARM) model. Aquaculture 264, 160-174. doi:10.1016/j.aquaculture.2006.12.017

Fuentes-Santos, I., Cubillo, A.M., Fernández-Reiriz, M.J., Labarta, U., 2013. Dynamic self-thinning model for sessile animal populations with multilayered distribution. Rev. Aquac. n/a-n/a. doi:10.1111/raq.12032

Hastie, T.J., Tibshirani, R.J., 1990. Generalized Additive Models. Chapman and Hall/CRC.

Hawkins, A.J.S., Pascoe, P.L., Parry, H., Brinsley, M., Black, K.D., McGonigle, C., Moore, H., Newell, C.R., O’Boyle, N., Ocarroll, T., O’Loan, B., Service, M., Smaal, A.C., Zhang, X.L., Zhu, M.Y., 2013. Shellsim: A Generic Model of Growth and Environmental Effects Validated Across Contrasting Habitats in Bivalve Shellfish. J. Shellfish Res. 32, 237-253. doi:10.2983/035.032.0201

Iliyasu, A., Mohamed, Z.A., Ismail, M.M., Abdullah, A.M., Kamarudin, S.M., Mazuki, H., 2014. A review of production frontier research in aquaculture (2001-2011). Aquac. Econ. Manag. 18, 221-247. doi:10.1080/13657305.2014.926464

Labarta, U., Fernández-Reiriz, Pérez-Camacho, Alejandro, Pérez-Corbacho, E., 2004. Bateeiros, mar, mejillón. Una perspectiva bioeconómica., Serie Estudios Sectoriales. Fundación Caixa Galicia., A Coruña, Spain. 
513 Meeusen, W., Broeck, J. van D., 1977. Efficiency Estimation from Cobb-Douglas

514 Production Functions with Composed Error. Int. Econ. Rev. 18, 435-444.

515 doi: $10.2307 / 2525757$

516 Murillo-Zamorano, L.R., Vega-Cervera, J.A., 2001. The use of parametric and non-

517 parametric frontier methods to measure the productive efficiency in the

518 industrial sector: A comparative study. Int. J. Prod. Econ. 69, 265-275.

519 doi:10.1016/S0925-5273(00)00027-X

520 Nobre, A.M., Musango, J.K., de Wit, M.P., Ferreira, J.G., 2009. A dynamic ecological-

521 economic modeling approach for aquaculture management. Ecol. Econ. 68,

$522 \quad 3007-3017$. doi:10.1016/j.ecolecon.2009.06.019

523 Pérez-Camacho, A., Labarta, U., Vinseiro, V., Fernández-Reiriz, M.J., 2013. Mussel

524 production management: Raft culture without thinning-out. Aquaculture 406-

$525 \quad 407,172-179$. doi:10.1016/j.aquaculture.2013.05.019

526 R Core Team, 2013. R: A Language and Environment for Statistical Computing. R

527 Foundation for Statistical Computing, Viena-, Austria.

528 Shephard, R.W., 1970. Theory of Cost and Production Functions. University Press.

529 Simar, L., Wilson, P.W., 1998. Sensitivity Analysis of Efficiency Scores: How to

530 Bootstrap in Nonparametric Frontier Models. Manag. Sci. 44, 49-61.

$531 \quad$ doi:10.1287/mnsc.44.1.49

532 Simar, L., Wilson, P.W., 1999. Estimating and bootstrapping Malmquist indices. Eur. J.

533 Oper. Res. 115, 459-471. doi:10.1016/S0377-2217(97)00450-5

534 Simar, L., Wilson, P.W., 2000. Statistical Inference in Nonparametric Frontier Models:

535 The State of the Art. J. Product. Anal. 13, 49-78.

536 doi:10.1023/A:1007864806704 
537 Troell, M., Naylor, R.L., Metian, M., Beveridge, M., Tyedmers, P.H., Folke, C., Arrow,

538 K.J., Barrett, S., Crépin, A.-S., Ehrlich, P.R., Gren, A., Kautsky, N., Levin, S.A.,

539 Nyborg, K., Osterblom, H., Polasky, S., Scheffer, M., Walker, B.H.,

540 Xepapadeas, T., de Zeeuw, A., 2014. Does aquaculture add resilience to the

541 global food system? Proc. Natl. Acad. Sci. U. S. A. 111, 13257-13263.

542 doi:10.1073/pnas. 1404067111

543 Wilson, P.W., 2008. FEAR: A software package for frontier efficiency analysis with R.

$544 \quad$ Socioecon. Plann. Sci. 42, 247-254.

545 Wood, S., 2006a. Generalized Additive Models: An Introduction with R. CRC Press.

546 Wood, S., 2006b. Low-rank scale-invariant tensor product smooths for generalized

547 additive mixed models. Biometrics 62, 1025-1036. doi:10.1111/j.1541-

$548 \quad 0420.2006 .00574 . x$

549

550 


\section{APPENDIX I}

\section{Culture costs}

553 Figure A1 shows total (€/rope) and marginal costs $(€ / \mathrm{Kg})$ for each density treatment 554 along the culture period. Total and occupation costs increase linearly over time, while 555 labour and transport can be considered constant over time. Total, labour and transport 556 costs increased with stocking density, while occupation costs remain constant along the 557 density gradient. However, marginal costs decreased with stocking density. 

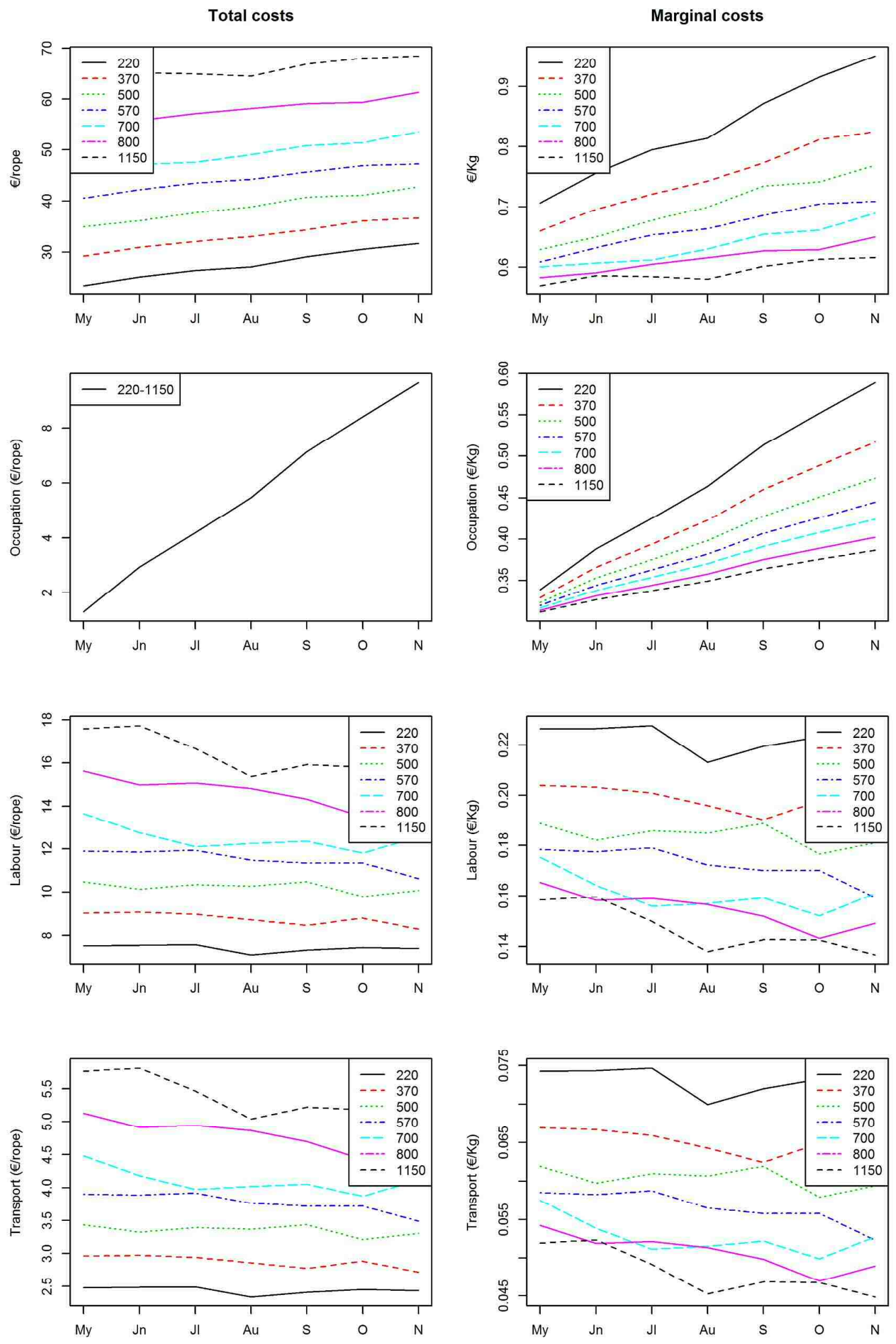

Fig A 1: Total ( $€ /$ rope) and marginal $(€ / \mathrm{Kg})$ production costs by months and density treatment. 


\section{APPENDIX II}

563 Parametric approach: Stochastic frontier production function (SFPF) with a model for 564 technical inefficiency effects In order to estimate the potential production and efficiency levels of the different 566 density treatments we applied one-step stochastic frontier analysis assuming a translog 567 frontier function with a model for inefficiency, which is assumed to depend on the 568 density treatments (Battese and Broca, 1997; Battese and Coelli, 1995) Our model can 569 be expressed as follows

$$
Y_{i t}=\exp \left(f\left(X_{i t}\right)+v_{i t}-u_{i t}\right)
$$

571 where $Y_{i t}$ is the output expressed as harvest production ( $\left.\mathrm{Kg} / \mathrm{rope}\right)$ for the i-th density 572 treatment at time $t, X_{i t}$ : is the vector of inputs, in our case stocking biomass $\left(X_{1}\right)$ and 573 cycle length $\left(X_{2}\right), V_{i t}$ is the stochastic error term and $U_{i t}$ is the estimate of the technical 574 inefficiency $T E_{i t}=\exp \left(-U_{i t}\right)$. The stochastic error term are assumed to be independent 575 and identically distributed $N\left(0, \sigma_{v}{ }^{2}\right)$ and independent of $U_{t i}$. The distribution of the 576 inefficiency error term is a truncation (at zero) of the normal distribution with mean $\mu=$ $577 z_{i t} \delta$ and variance $\sigma_{\mathrm{u}}^{2}$, i.e $U_{i t}=z_{i t} \delta+W_{i t}$, where, $\mathrm{z}_{\mathrm{it}}$ is the vector of variables that may 578 affect technical inefficiency, $\delta$ is the associated vector of parameters and $W_{i t}$ are random 579 error terms $\left(N\left(0, \sigma_{w}{ }^{2}\right)\right)$. Positive coefficients $(\delta>0)$ indicate relative technical 580 inefficiency while negative coefficients $(\delta<0)$ point out relative technical efficiency. 581 The more the estimated value differs from zero, the stronger the efficiency/inefficiency. 582 In this study, initial density was introduced as dummy variable to account for differences in efficiency across the density gradient. 
585 , is the translog production frontier function:

586

$$
\begin{aligned}
\ln Y_{i t} & =\beta_{0}+\beta_{1} \ln X_{1 i t}+\beta_{2} \ln X_{2 i t} \\
& +\frac{1}{2}\left(\beta_{11}\left(\ln X_{1 i t}\right)^{2}+2 \beta_{12} \ln X_{1 i t} \ln X_{2 i t}+\beta_{22}\left(\ln X_{2 i t}\right)^{2}\right)+v_{i t}-u_{i t}
\end{aligned}
$$

587 where the interaction between stocking biomass and cycle length implies non-neutral 588 technical change. If all $\beta_{\mathrm{jk}}=0$, then the previous model reduces to a Cobb-Douglas $(\mathrm{C}-$ 589 D) SFPF model:

The parameters of the stochastic frontier and the model for the technical inefficiency effects were simultaneously estimated by maximum likelihood. The

592 likelihood function is expressed in terms of the variance parameters $\sigma^{2}=\sigma_{v}{ }^{2}+\sigma_{u}{ }^{2}$ and $593 \gamma=\sigma_{u} / \sigma$, which measures the proportion of deviation from the frontier due to technical inefficiency (Battese and Coelli, 1993). Model selection for the frontier function and the inefficiency effects were performed by one-side generalized likelihood-ratio tests (LR):

596

$$
L R=-2\left\{\ln \left\{L\left(H_{0}\right) / L\left(H_{1}\right)\right\}\right\}=-2\left\{\ln \left[L\left(H_{0}\right)\right]-\ln \left[L\left(H_{1}\right)\right]\right\} \sim \chi^{2}
$$

Where $L\left(H_{0}\right)$ and $L\left(H_{1}\right)$ are the likelihood functions under the null and alternative hypotheses, respectively. The stochastic frontier model selection was conducted testing the null hypothesis: $\mathrm{H}_{0}: \beta_{\mathrm{jk}}=0$, i.e. testing whether the translog SFPF (eq. 3) can be reduced to a Cobb-Douglas SFPF. The inefficiency model selection was conducted by the following multistage hypothesis test:

1. $\mathrm{H}_{0}: \gamma=\delta_{0}=\delta_{1}=\ldots=\delta_{7}=0$, which implies total efficiency, i.e. the model can be 
$6062 . \mathrm{H}_{0}: \gamma=0$, which implies that the inefficiencies are not stochastic.

$6073 . \mathrm{H}_{0}: \delta_{1}=\ldots=\delta_{7}=0$, which implies that the inefficiency effects are independent of 608 the density treatment.

609

The output elasticity for each input factor, $X_{j}(j=1,2)$, defined as the percentage change of the $\mathrm{i}$-th output at time $t$ for a $1 \%$ change in the $\mathrm{j}$-th input, is given by:

$$
E X_{j i t}=\frac{\partial \ln \left(Y_{i t}\right)}{\partial \ln \left(X_{j i t}\right)}=\frac{\partial Y_{i t}}{\partial X_{j i t}} \frac{X_{j i t}}{Y_{i t}}=\beta_{j}+\sum_{k=1}^{m} \beta_{j k} \ln \left(X_{k i t}\right)
$$

Since for the translog SFPF, $E X_{j i t}$ is different for each treatment and time, we use the sample mean of each input factor across all treatments and times, $E X_{j}$ to represent $E X_{j i t}$. The sum of these parameters is the return to scale (RTS), which measures the percentage change in output from a $1 \%$ change in all input factors. When RTS $>1$ (RTS $<1$ ) the production function exhibits increasing (decreasing) returns to scale, i.e. a simultaneous increase in all inputs by a certain percentage results in greater (lower) percentage increase in output. If RTS $=1$, the farm present constant returns to scale, implying that a proportionate increase in inputs will lead to the same increase in output. the translog SFPF (eq. 3) model is defined as:

$$
H_{j k}=\frac{\beta_{j k}}{E X_{j}+E X_{k}}-1
$$

$625 H_{12}>0$ indicates that the inputs are jointly complementary, i.e. we need to increase stocking biomass and cycle length together to raise total production. $H_{j k}<0$ indicates a 
627 competitive relationship between inputs, i.e. a decrease in stocking biomass could be 628 compensated elongating the culture period.

629 The economic efficiency of an input can be analyzed by comparison between the 630 incremental benefit of an additional unit and its incremental cost. Assuming constant 631 unit input cost, $\mathrm{P}_{\mathrm{x}}$, and output price, $\mathrm{P}_{\mathrm{y}}$, the value of marginal product (VMP) is defined 632 as:

$$
V M P_{i t}=M P P_{i t} \cdot P_{y}
$$

634 where MPP is the marginal physical product, which according to Ferguson, (2008) is 635 equal to the elasticity of scale. If the value of the marginal product (VMP) of an input is 636 greater than its price $\left(\mathrm{P}_{\mathrm{x}}\right)$, profit could be increased by increasing the use of that input, 637 and conversely. To achieve efficient use of an input, the value of its marginal product 638 should be equal to its price.

639

640 
641 Table 1: Summary of production costs included in the efficiency models.

\begin{tabular}{cccc}
\hline €/rope & Min (220 ind/m) & Mean (sd) & Max (1150 ind/m) \\
\hline Mussel & 10.5 & $23.43(8.77)$ & 39.9 \\
Labour & 6.7 & $11.62(3.02)$ & 18.67 \\
Transport & 2.2 & $3.81(0.99)$ & 6.13 \\
Occupation & & $1.38 € /$ month \\
\hline
\end{tabular}

642

643

Table 2: Hypothesis test for stochastic production function and inefficiency models.

645

\begin{tabular}{|c|c|c|c|c|c|c|}
\hline $\mathbf{H}_{\mathbf{O}}$ & $\operatorname{loglik} \mathbf{H}_{0}$ & $\operatorname{loglik} \mathrm{H}_{1}$ & df & LR & p-value & \\
\hline CD vs translog & 93.374 & 106.316 & 3 & 25.883 & $1.01 \mathrm{E}-05$ & $* * *$ \\
\hline$\gamma=\boldsymbol{\delta}_{1}=\ldots=\boldsymbol{\delta}_{7}=\mathbf{0}$ & 76.699 & 106.316 & 8 & 59.235 & $2.88 \mathrm{E}-10$ & $* * *$ \\
\hline$\gamma=\mathbf{0}$ & 76.699 & 83.901 & 3 & 14.406 & 0.001 & $* *$ \\
\hline$\dot{\delta}_{1}=\ldots=\delta_{7}=0$ & 76.718 & 106.316 & 6 & 59.196 & $6.55 \mathrm{E}-11$ & $* * *$ \\
\hline
\end{tabular}

646

647 Table 3: Model parameters, output elasticities and technical efficiencies for the translog 648 SFPF.

\begin{tabular}{lrrr}
\hline & Parameter & p-value & \\
\hline Elacticies & & & \\
$\quad$ Stocking rate & 0.473 & $<2.2 \mathrm{e}-16$ & $* * *$ \\
Days & 0.500 & $<2.2 \mathrm{e}-16$ & $* * *$ \\
RTS & 0.973 & 0.057 & \\
& & & \\
$\boldsymbol{\sigma}^{2}$ & 0.0198 & $<2.2 \mathrm{e}-16$ & $* * *$ \\
$\boldsymbol{\gamma}$ & 0.0114 & $<2.2 \mathrm{e}-16$ & $* * *$
\end{tabular}

Inefficiency factors $(\delta)$

TE

$$
220
$$

370

0.725

5

7.67E-10

$* * * \quad 0.484$

500

0.347

0.0002

0.164

0.0429

570

0.163

0.0187

$*$

700

0.084

0.1502

0.132

$$
0.0026
$$

$-1.025$

$1.68 \mathrm{E}-06$

0.707

1150

$$
(* \overline{* *}) \mathrm{p} \text {-value }<0.001,\left({ }^{* *}\right) \mathrm{p} \text {-value }<0.01,\left({ }^{*}\right) \mathrm{p} \text {-value }<0.05 \text {. }
$$

650 
651 Table 4: Changes in productivity, efficiency and technology for total production.

652 Number greater (lower) than 1 indicate progress (regress).

\begin{tabular}{|c|c|c|c|c|c|c|c|c|c|c|c|c|}
\hline \multicolumn{13}{|c|}{ Total production (kg/rope) } \\
\hline \multicolumn{13}{|c|}{ Malmquist indices } \\
\hline & M-Jn & & Jn-J1 & & $\mathrm{J} l-\mathrm{Au}$ & & $\mathrm{Au}-\mathrm{S}$ & & $\mathrm{S}-\mathrm{O}$ & & $\mathrm{O}-\mathrm{N}$ & \\
\hline 220 & 1.788 & $* *$ & 1.294 & $* *$ & 0.986 & $* *$ & 1.253 & $* *$ & 1.219 & $* *$ & 0.989 & $* *$ \\
\hline 370 & 1.555 & $* *$ & 1.323 & $* *$ & 1.141 & $* *$ & 1.216 & $* *$ & 1.113 & ** & 0.911 & $* *$ \\
\hline 500 & 1.500 & $* *$ & 1.327 & $* *$ & 1.202 & $* *$ & 1.181 & ** & 0.917 & $* *$ & 1.077 & ** \\
\hline 570 & 1.800 & $* *$ & 1.147 & $* *$ & 1.273 & $* *$ & 0.992 & & 1.001 & & 0.911 & $* *$ \\
\hline 700 & 1.458 & $* *$ & 1.156 & $* *$ & 1.202 & $* *$ & 1.168 & $* *$ & 0.860 & $* *$ & 1.381 & $* *$ \\
\hline 800 & 1.454 & $* *$ & 1.371 & $* *$ & 1.208 & $* *$ & 1.032 & $* *$ & 0.831 & $* *$ & 1.312 & $* *$ \\
\hline 1150 & 2.041 & $* *$ & 1.037 & $* *$ & 1.208 & $* *$ & 1.207 & $* *$ & 0.852 & $* *$ & 1.094 & $* *$ \\
\hline \multicolumn{13}{|c|}{ Efficiency } \\
\hline & M-Jn & & Jn-J1 & & $\mathrm{J} 1-\mathrm{Au}$ & & $\mathrm{Au}-\mathrm{S}$ & & S-O & & $\mathrm{O}-\mathrm{N}$ & \\
\hline 220 & 1.107 & $* *$ & 1.042 & $* *$ & 0.819 & $* *$ & 1.051 & & 1.183 & $* *$ & 0.955 & \\
\hline 370 & 0.963 & & 1.065 & $* *$ & 0.947 & $* *$ & 1.021 & & 1.096 & & 0.880 & $* *$ \\
\hline 500 & 0.929 & $* *$ & 1.082 & $* *$ & 1.000 & & 1.000 & & 0.981 & & 0.957 & \\
\hline 570 & 1.114 & $* *$ & 0.982 & & 1.031 & & 0.864 & $* *$ & 1.099 & $* *$ & 0.756 & $* *$ \\
\hline 700 & 0.903 & $* *$ & 1.045 & $* *$ & 0.983 & $* *$ & 0.997 & & 0.965 & $*$ & 1.121 & $* *$ \\
\hline 800 & 0.814 & $* *$ & 1.285 & $* *$ & 0.994 & & 0.858 & $* *$ & 0.952 & $* *$ & 1.137 & $* *$ \\
\hline 1150 & 1.087 & & 1.000 & & 1.000 & & 1.000 & & 1.000 & & 1.000 & \\
\hline \multicolumn{13}{|c|}{ Technology } \\
\hline & M-Jn & & Jn-J1 & & $\mathrm{J} 1-\mathrm{Au}$ & & $\mathrm{Au}-\mathrm{S}$ & & $\mathrm{S}-\mathrm{O}$ & & $\mathrm{O}-\mathrm{N}$ & \\
\hline 220 & 1.615 & $* *$ & 1.242 & $* *$ & 1.205 & $* *$ & 1.192 & $* *$ & 1.030 & & 1.036 & \\
\hline 370 & 1.615 & $* *$ & 1.242 & $* *$ & 1.205 & $* *$ & 1.192 & $* *$ & 1.015 & & 1.036 & \\
\hline 500 & 1.615 & $* *$ & 1.227 & $* *$ & 1.202 & $* *$ & 1.181 & $* *$ & 0.935 & $* *$ & 1.125 & $* *$ \\
\hline 570 & 1.615 & $* *$ & 1.168 & $* *$ & 1.235 & $* *$ & 1.148 & $* *$ & 0.911 & $* *$ & 1.205 & $* *$ \\
\hline 700 & 1.615 & $* *$ & 1.106 & $* *$ & 1.222 & $* *$ & 1.171 & $* *$ & 0.891 & $*$ & 1.233 & $* *$ \\
\hline 800 & 1.787 & $* *$ & 1.067 & & 1.215 & $* *$ & 1.202 & $* *$ & 0.873 & $* *$ & 1.154 & $*$ \\
\hline 1150 & 1.878 & $* *$ & 1.037 & & 1.208 & $* *$ & 1.207 & $* *$ & 0.852 & $* *$ & 1.094 & \\
\hline
\end{tabular}


654 Table 5: Changes in productivity, efficiency and technology for fresh sale revenues.

655 Number greater (lower) than 1 indicate progress (regress).

\begin{tabular}{|c|c|c|c|c|c|c|c|c|c|c|c|c|}
\hline \multicolumn{13}{|c|}{ Fresh sale (€/rope) } \\
\hline \multicolumn{13}{|c|}{ Malmquist index } \\
\hline & M-Jn & & $\mathrm{Jn}-\mathrm{J} 1$ & & $\mathrm{Jl}-\mathrm{Au}$ & & $\mathrm{Au}-\mathrm{S}$ & & $\mathrm{S}-\mathrm{O}$ & & $\mathrm{O}-\mathrm{N}$ & \\
\hline 220 & NA & & 1.498 & $* *$ & 1.279 & $* *$ & 1.253 & $* *$ & 1.330 & $* *$ & 0.997 & $* *$ \\
\hline 370 & 6.014 & $* *$ & 1.403 & $* *$ & 1.291 & $* *$ & 1.672 & $* *$ & 1.003 & & 1.093 & $* *$ \\
\hline 500 & 2.807 & $* *$ & 1.413 & $* *$ & 1.361 & $* *$ & 1.403 & $* *$ & 0.963 & $* *$ & 1.074 & $* *$ \\
\hline 570 & NA & & 1.214 & $* *$ & 1.546 & $* *$ & 1.116 & $* *$ & 1.040 & $* *$ & 0.910 & $* *$ \\
\hline 700 & NA & & 1.320 & $* *$ & 1.331 & $* *$ & 1.367 & $* *$ & 0.858 & $* *$ & 1.581 & $* *$ \\
\hline 800 & NA & & 1.335 & $* *$ & 1.437 & $* *$ & 1.239 & $* *$ & 0.823 & $* *$ & 1.447 & $* *$ \\
\hline 1150 & NA & & 1.340 & $* *$ & 1.452 & $* *$ & 1.500 & $* *$ & 0.722 & $* *$ & 1.291 & $* *$ \\
\hline \multicolumn{13}{|c|}{ Efficiency } \\
\hline & M-Jn & & $\mathrm{Jn}-\mathrm{J} 1$ & & $\mathrm{~J} 1-\mathrm{Au}$ & & $\mathrm{Au}-\mathrm{S}$ & & $\mathrm{S}-\mathrm{O}$ & & $\mathrm{O}-\mathrm{N}$ & \\
\hline 220 & NA & & 1.122 & $* *$ & 0.893 & $* *$ & 0.876 & $* *$ & 1.303 & $*$ & 0.831 & $* *$ \\
\hline 370 & 2.004 & $* *$ & 1.051 & & 0.901 & $* *$ & 1.177 & $* *$ & 1.000 & & 0.911 & $*$ \\
\hline 500 & 0.935 & & 1.069 & $* *$ & 0.950 & & 1.026 & & 1.025 & & 0.810 & $* *$ \\
\hline 570 & NA & & 0.955 & & 1.047 & & 0.843 & $* *$ & 1.186 & $* *$ & 0.620 & $* *$ \\
\hline 700 & NA & & 1.000 & & 0.944 & $*$ & 0.991 & & 1.049 & $* *$ & 1.019 & \\
\hline 800 & NA & & 1.005 & & 1.015 & & 0.853 & $* *$ & 1.078 & $* *$ & 0.966 & \\
\hline 1150 & NA & & 1.000 & & 1.000 & & 1.000 & & 1.000 & & 0.886 & $* *$ \\
\hline \multicolumn{13}{|c|}{ Technology } \\
\hline & M-Jn & & Jn-J1 & & $\mathrm{J} 1-\mathrm{Au}$ & & $\mathrm{Au}-\mathrm{S}$ & & S-O & & $\mathrm{O}-\mathrm{N}$ & \\
\hline 220 & NA & & 1.335 & $* *$ & 1.432 & $* *$ & 1.429 & $* *$ & 1.021 & & 1.200 & $* *$ \\
\hline 370 & 3.001 & $* *$ & 1.335 & $* *$ & 1.432 & $* *$ & 1.420 & $* *$ & 1.003 & & 1.200 & $* *$ \\
\hline 500 & 3.001 & $* *$ & 1.322 & $* *$ & 1.432 & $* *$ & 1.367 & $* *$ & 0.939 & $* *$ & 1.325 & $* *$ \\
\hline 570 & NA & & 1.271 & $* *$ & 1.476 & $* *$ & 1.323 & $* *$ & 0.877 & $* *$ & 1.469 & $* *$ \\
\hline 700 & NA & & 1.320 & $* *$ & 1.409 & $* *$ & 1.379 & $* *$ & 0.818 & $* *$ & 1.551 & $* *$ \\
\hline 800 & NA & & 1.329 & $* *$ & 1.415 & $* *$ & 1.452 & $* *$ & 0.763 & $* *$ & 1.499 & $* *$ \\
\hline 1150 & NA & & 1.340 & $* *$ & 1.452 & $* *$ & 1.500 & $* *$ & 0.722 & $* *$ & 1.456 & $* *$ \\
\hline
\end{tabular}


657 Table 6: Changes in productivity, efficiency and technology for industry sale revenues.

658 Number greater (lower) than 1 indicate progress (regress).

\begin{tabular}{|c|c|c|c|c|c|c|c|c|c|c|c|c|}
\hline \multicolumn{13}{|c|}{ Industry (€/rope) } \\
\hline \multicolumn{13}{|c|}{ Malmquist indices } \\
\hline & M-Jn & & $\mathrm{Jn}-\mathrm{J} 1$ & & $\mathrm{~J} 1-\mathrm{Au}$ & & $\mathrm{Au}-\mathrm{S}$ & & $\mathrm{S}-\mathrm{O}$ & & $\mathrm{O}-\mathrm{N}$ & \\
\hline 220 & 2.986 & $* *$ & 1.374 & $* *$ & 1.023 & $* *$ & 1.138 & $* *$ & 1.011 & $* *$ & 0.957 & $* *$ \\
\hline 370 & 2.649 & $* *$ & 1.399 & $* *$ & 1.083 & $* *$ & 1.180 & $* *$ & 0.965 & $* *$ & 0.811 & $* *$ \\
\hline 500 & 3.133 & $* *$ & 1.418 & $* *$ & 1.210 & $* *$ & 1.003 & $* *$ & 0.892 & $* *$ & 0.960 & $* *$ \\
\hline 570 & 4.087 & $* *$ & 1.219 & $* *$ & 1.341 & $* *$ & 0.782 & $* *$ & 0.900 & $* *$ & 0.890 & $* *$ \\
\hline 700 & 2.378 & $* *$ & 1.168 & $* *$ & 1.128 & $* *$ & 1.093 & $* *$ & 0.772 & $* *$ & 1.321 & $* *$ \\
\hline 800 & 3.281 & $* *$ & 1.464 & $* *$ & 1.187 & $* *$ & 0.982 & $* *$ & 0.703 & $* *$ & 1.314 & $* *$ \\
\hline 1150 & 4.588 & $* *$ & 1.122 & $* *$ & 1.171 & $* *$ & 1.160 & $* *$ & 0.633 & $* *$ & 1.193 & $* *$ \\
\hline \multicolumn{13}{|c|}{ Efficiency } \\
\hline & M-Jn & & $\mathrm{Jn}-\mathrm{Jl}$ & & $\mathrm{J} 1-\mathrm{Au}$ & & $\mathrm{Au}-\mathrm{S}$ & & $\mathrm{S}-\mathrm{O}$ & & $\mathrm{O}-\mathrm{N}$ & \\
\hline 220 & 1.174 & $* *$ & 1.035 & & 0.813 & $* *$ & 1.172 & $* *$ & 1.032 & & 1.003 & \\
\hline 370 & 1.042 & $*$ & 1.054 & $* *$ & 0.862 & $* *$ & 1.216 & $* *$ & 1.000 & & 0.849 & $* *$ \\
\hline 500 & 1.232 & $* *$ & 1.080 & $* *$ & 0.962 & $*$ & 1.039 & & 1.000 & & 0.926 & $*$ \\
\hline 570 & 1.607 & $* *$ & 0.972 & & 1.029 & & 0.816 & $* *$ & 1.112 & $* *$ & 0.775 & $* *$ \\
\hline 700 & 0.935 & & 0.980 & & 0.903 & $* *$ & 1.068 & & 1.042 & $* *$ & 1.086 & $* *$ \\
\hline 800 & 1.166 & $* *$ & 1.271 & $* *$ & 0.977 & $* *$ & 0.891 & $* *$ & 1.037 & $* *$ & 1.091 & $* *$ \\
\hline 1150 & 1.551 & $* *$ & 1.000 & & 1.000 & & 1.000 & & 1.000 & & 1.000 & \\
\hline \multicolumn{13}{|c|}{ Technology } \\
\hline & M-Jn & & $\mathrm{Jn}-\mathrm{J} 1$ & & $\mathrm{~J} 1-\mathrm{Au}$ & & $\mathrm{Au}-\mathrm{S}$ & & $\mathrm{S}-\mathrm{O}$ & & $\mathrm{O}-\mathrm{N}$ & \\
\hline 220 & 2.544 & $* *$ & 1.328 & $* *$ & 1.257 & $* *$ & 0.971 & & 0.980 & & 0.955 & \\
\hline 370 & 2.544 & $* *$ & 1.328 & $* *$ & 1.257 & $* *$ & 0.970 & & 0.965 & & 0.955 & \\
\hline 500 & 2.544 & $* *$ & 1.313 & $* *$ & 1.257 & $* *$ & 0.965 & & 0.892 & $* *$ & 1.036 & \\
\hline 570 & 2.544 & $* *$ & 1.254 & $* *$ & 1.303 & $* *$ & 0.959 & & 0.809 & $* *$ & 1.148 & $* *$ \\
\hline 700 & 2.544 & $* *$ & 1.191 & $* *$ & 1.249 & $* *$ & 1.024 & & 0.740 & $* *$ & 1.217 & $* *$ \\
\hline 800 & 2.815 & $* *$ & 1.152 & $* *$ & 1.214 & $* *$ & 1.102 & $* *$ & 0.678 & $* *$ & 1.204 & $* *$ \\
\hline 1150 & 2.958 & $* *$ & 1.122 & $*$ & 1.171 & $* *$ & 1.160 & $* *$ & 0.633 & $* *$ & 1.193 & $* *$ \\
\hline
\end{tabular}




\section{Figure captions}

661 Fig. 1. Interaction plots of density (ind/m), total production $(\mathrm{Kg} / \mathrm{rope})$, individuals per 662 kilogram of mussels (ind/ $\mathrm{Kg}$ ), individuals per kilogram of tissue (ind/ $\mathrm{Kg}$ of tissue), 663 condition index $(\%)$, fresh and industry sale prices $(€ / \mathrm{Kg})$ and costs $(€ /$ rope $)$.

664 Fig. 2: GAM fit showing the effect of stocking biomass (Kg/rope) and cycle length 665 (days) on fresh sale and industry sale profits ( $€ /$ rope).

666 Fig. 3: GAM fits for the temporal evolution of profits obtained by fresh (black) and 667 industry sale (red) by density treatment.

668 Fig. 4: Top: Marginal costs $\left(\mathrm{P}_{\mathrm{x}}\right.$ left) and VMP indices for total production of stocking 669 biomass for fresh (centre) and industry (right) sale. Bottom: ratio between VMP and 670 marginal costs for fresh and industry sale.

671 Fig. 5: Malmquist productivity, efficiency and technology indices for total production 672 (top), fresh sale revenues (centre) and industry sale revenues (bottom). 
a

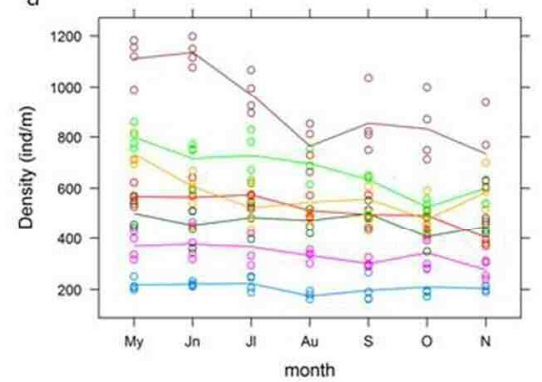

c

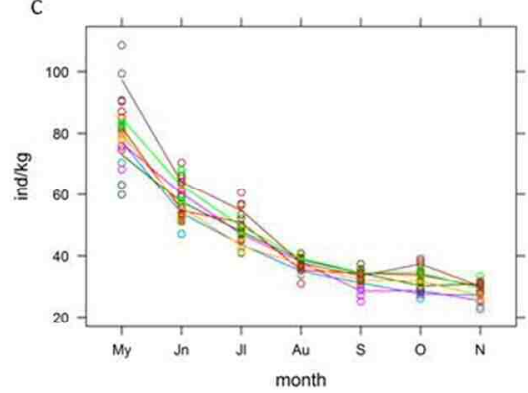

e

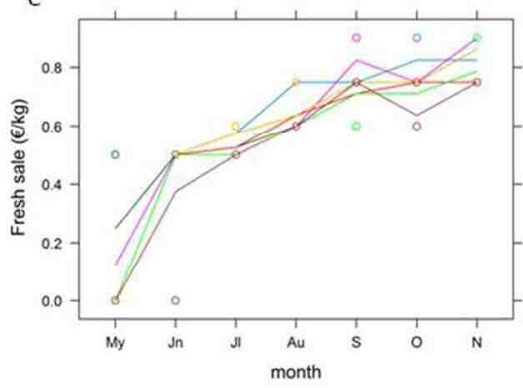

b

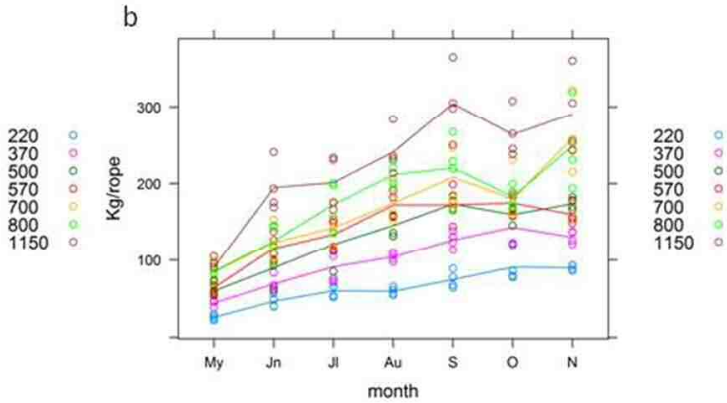

d
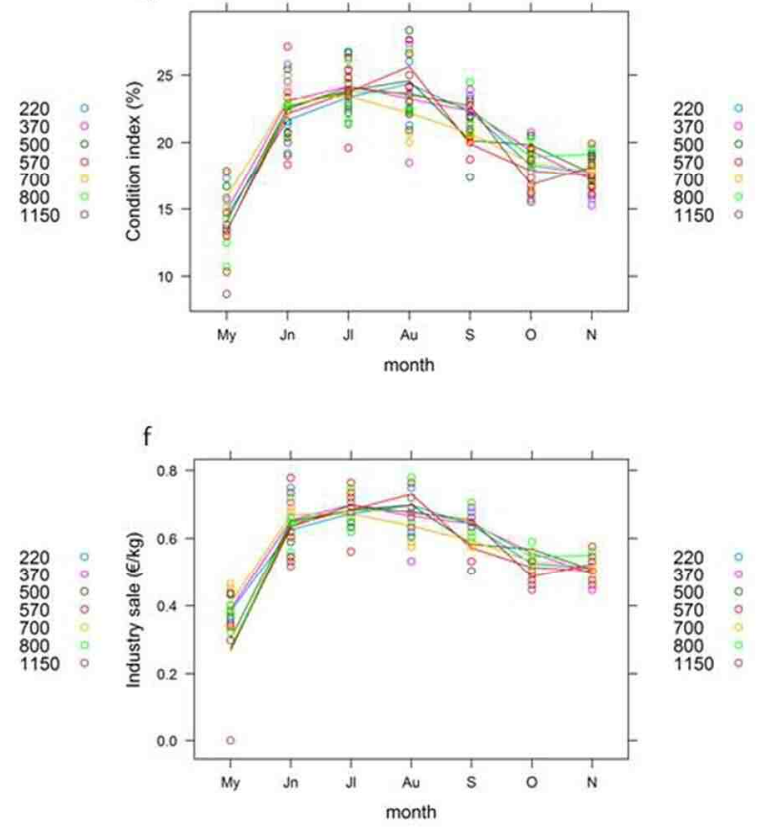

Fig. 1. Interaction plots of density (ind/m), total production ( $\mathrm{Kg} / \mathrm{rope}$ ), individuals per kilogram of mussels (ind $/ \mathrm{Kg}$ ), individuals per kilogram of tissue (ind/Kg of tissue), condition index (\%), fresh and industry sale prices $(€ / \mathrm{Kg})$ and costs $(€ /$ rope $)$. $151 \times 154 \mathrm{~mm}(150 \times 150 \mathrm{DPI})$ 

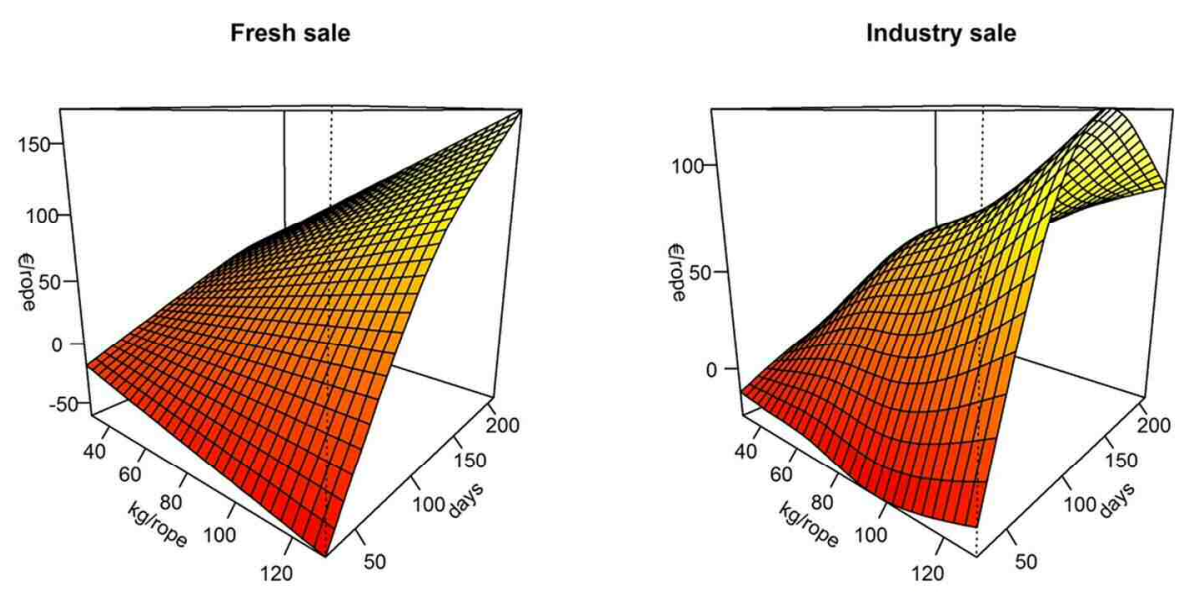

Fig. 2: GAM fit showing the effect of stocking biomass ( $\mathrm{Kg} / \mathrm{rope})$ and cycle length (days) on fresh sale and industry sale profits $(€ /$ rope) $99 \times 55 \mathrm{~mm}(300 \times 300$ DPI $)$ 

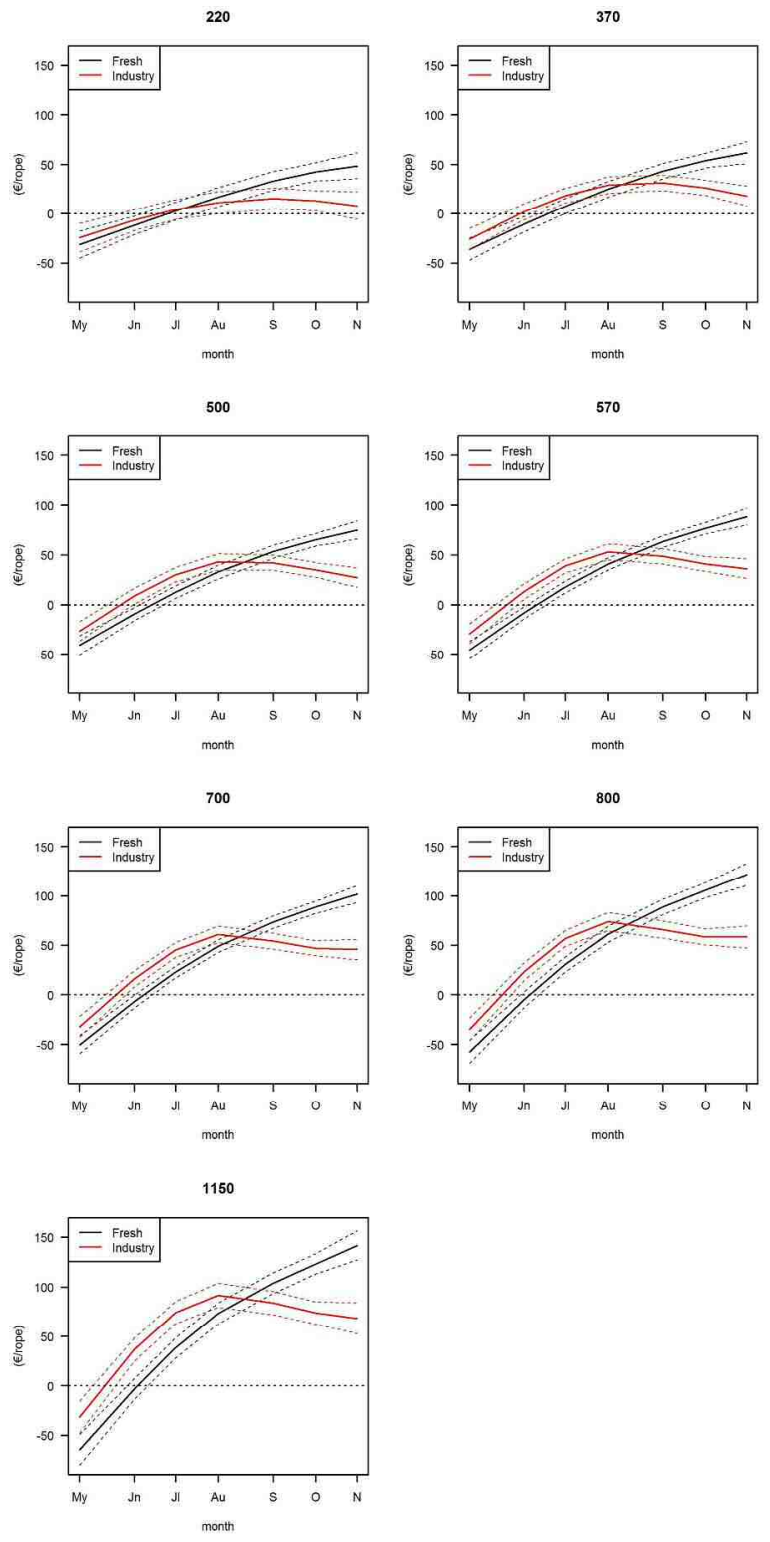

Fig. 3: GAM fits for the temporal evolution of profits obtained by fresh (black) and industry sale (red) by density treatment.

239x479mm (300 x 300 DPI) 

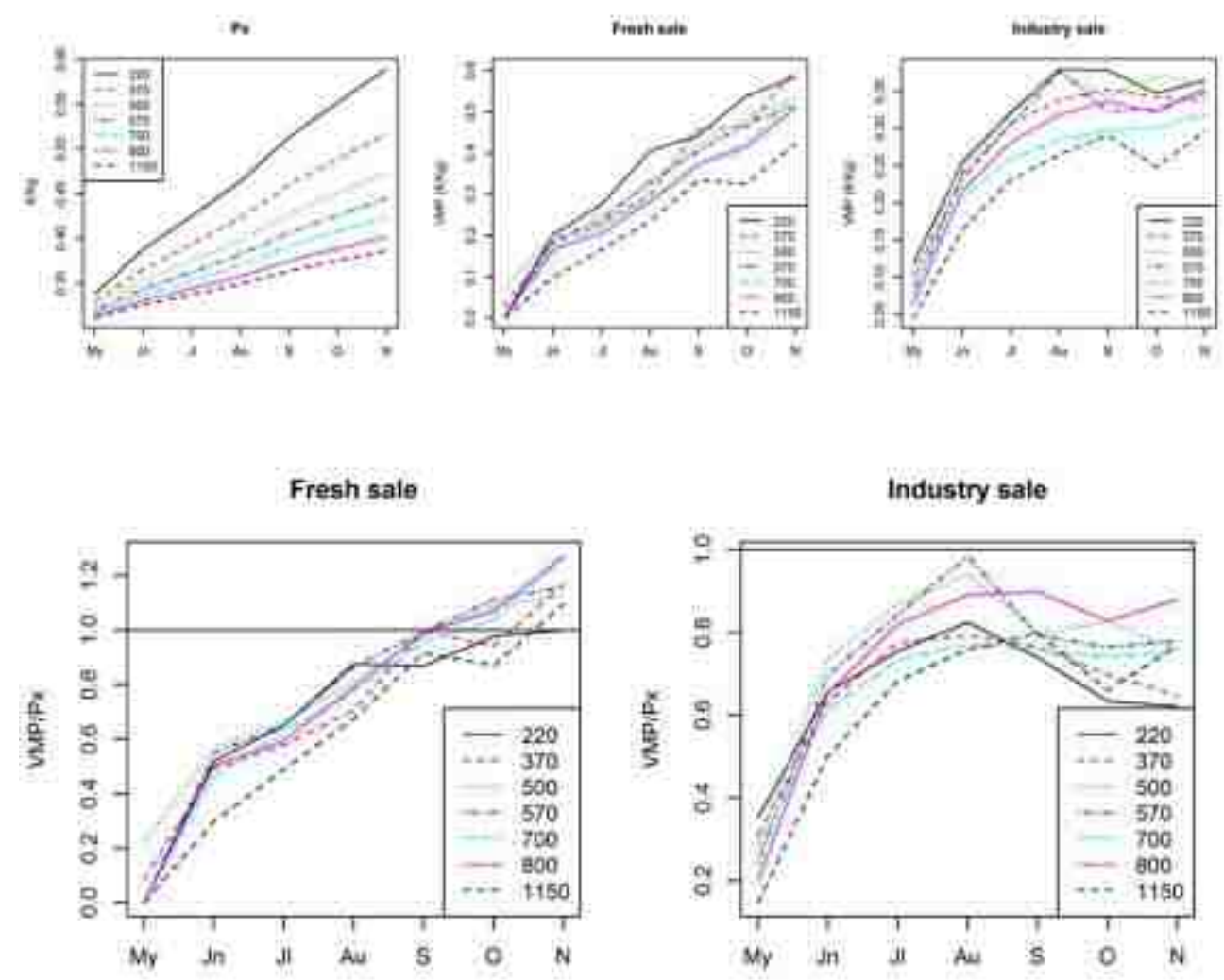

Fig. 4: Top: Marginal costs (Px left) and VMP indices for total production of stocking biomass for fresh (centre) and industry (right) sale. Bottom: ratio between VMP and marginal costs for fresh and industry sale. 

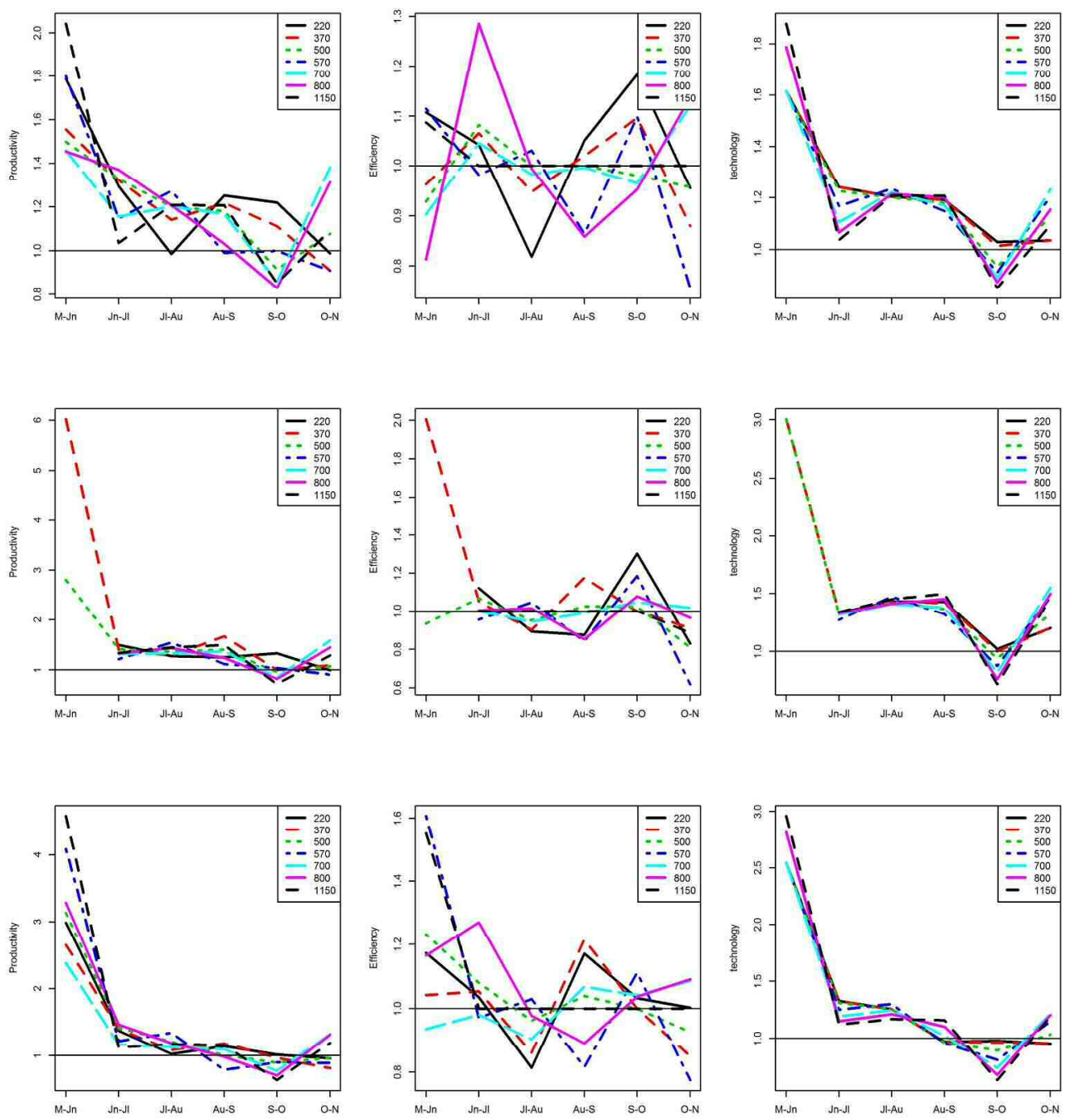

Fig. 5: Malmquist productivity, efficiency and technology indices for total production (top), fresh sale revenues (centre) and industry sale revenues (bottom). $219 \times 241 \mathrm{~mm}$ (300 x 300 DPI) 